\title{
Medical end-of-life practices among Canadian physicians: a pilot study
}

\author{
Isabelle Marcoux PhD, Antoine Boivin MD PhD, Laura Mesana MSc, Ian D. Graham PhD, \\ Paul Hébert MD MHSc
}

\section{Abstract}

Background: Medical end-of-life practices are hotly debated in Canada, and data from other countries are used to support arguments. The objective of this pilot study was twofold: to adapt and validate a questionnaire designed to measure the prevalence of these practices in Canada and the underlying decision-making process, and to assess the feasibility of a nationally representative study.

Methods: In phase 1, questionnaires from previous studies were adapted to the Canadian context through consultations with a multidisciplinary committee and based on a scoping review. The modified questionnaire was validated through cognitive interviews with 14 physicians from medical specialties associated with a higher probability of being involved with dying patients recruited by means of snowball sampling. In phase 2, we selected a stratified random sample of 300 Canadian physicians in active practice from a national medical directory and used the modified tailored method design for mail and Web surveys. There were 4 criteria for success: modified questions are clearly understood; response patterns for sensitive questions are similar to those for other questions; respondents are comparable to the overall sampling frame; and mean questionnaire completion time is less than 20 minutes.

Results: Phase 1: main modifications to the questionnaire were related to documentation of all other medical practices (including practices intended to prolong life) and a question on the proportionality of drugs used. The final questionnaire contained 45 questions in a booklet style. Phase 2: of the 280 physicians with valid addresses, $87(31.1 \%)$ returned the questionnaire; 11 of the 87 declined to participate, for a response rate of $27.1 \%(n=76)$. Most respondents (64 [84\%]) completed the mail questionnaire. All the criteria for success were met.

Interpretation: It is feasible to study medical end-of-life practices, even for practices that are currently illegal, including the intentional use of lethal drugs. Results from this pilot study support conducting a large national study, but additional strategies would be necessary to improve the response rate.

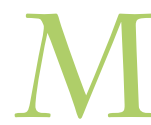
edical end-of-life practices are hotly debated in Canada, and changes in legislation at both the provincial and the federal levels have recently been adopted. In Quebec, An Act Respecting End-of-life Care, which took effect in December 2015, ${ }^{1}$ aims to clarify under which conditions the allowed medical end-of-life practices (e.g., withdrawing life-sustaining treatments, using drugs for symptom management) must be performed and also to legally authorize physicians to intentionally cause death by administering lethal drugs on the voluntary request of a terminally ill patient. In February 2015, the Supreme Court of Canada ruled that the federal Criminal Code prohibitions on physician-assisted death (prescription or administration of lethal drugs on the voluntary request of competent adults with a grievous and irremediable medical condition) were unconstitutional. ${ }^{2}$ The federal government introduced legislation in April 2016 under which adults with a "grievous and irremedi- able" condition will be able to request physician-assisted death. ${ }^{3}$ During parliamentary work and Court audience, data from the Netherlands and Belgium were used to support arguments. At that time, no empirical data on medical end-oflife practices in Canada were available; such data were declared impossible to collect, as some of the medical acts discussed were illegal.

Studies on the prevalence and characteristics of medical end-of-life practices, including the intentional use of lethal

\section{Competing interests: None declared.}

This article has been peer reviewed.

Correspondence to: Isabelle Marcoux, imarcoux@uottawa.ca CMAJ Open 2016. DOI:10.9778/cmajo.20150084 
drugs, are important to enlighten discussions regarding public policies on end of life and also to monitor these practices over time. Such studies were first conducted in the early 1990s in the Netherlands ${ }^{4}$ and have been replicated 4 times since then. ${ }^{5-8}$ Studies were also conducted in Belgium, both before $^{9,10}$ and after $^{11,12}$ the Belgian Act on Euthanasia ${ }^{13}$ was adopted. Other countries with restrictive policies regarding the intentional use of lethal drugs have also succeeded in collecting such data (Australia, ${ }^{14}$ Denmark,${ }^{10}$ France, ${ }^{15}$ Italy, ${ }^{10}$ the United Kingdom, ${ }^{16,17}$ the United States, ${ }^{18}$ New Zealand ${ }^{19}$ and Sweden ${ }^{10}$ ), with response rates ranging from $40 \%$ to $62 \%$. It thus seems feasible to study various medical end-of-life practices, regardless of their legal status. However, Canadian physicians appear less likely than physicians from other countries to participate in comparable surveys. ${ }^{20}$ Furthermore, the Canadian Medical Association's National Physician Survey showed a decrease in the rate of response by physicians, dropping from $36 \%$ in 2004 to $16 \%$ in $2014 .{ }^{21}$ Challenges can then be expected when studying controversial end-of-life medical practices and related sensitive issues in this country.

The objective of this pilot study was twofold. We first aimed to translate, adapt and validate for the Canadian context a research instrument developed in Europe. Second, we assessed the feasibility of conducting a nationally representative study. The criteria for success ${ }^{22}$ of this pilot study were: adapted questions are clearly understood by physicians; response patterns for sensitive questions are similar to those for other questions; survey participants are comparable to physicians in the overall sampling frame; and mean questionnaire completion time is less than 20 minutes. We also wished to document participation rates and potential biases attributable to low rates.

\section{Methods}

\section{Phase 1: questionnaire development}

\section{Questionnaire modification}

Questionnaire selection was based on previous validated studies $^{4-19}$ and was contingent on language (French or English) and variations of questions between them. In previous studies, ${ }^{4-19}$ questionnaires were mostly based on the original Dutch study. ${ }^{4}$ We selected the latest Belgian questionnaire because it has been validated in more than one study ${ }^{9,11}$ and has been validated in French. Significant changes were, however, recently made in studies conducted in France ${ }^{15}$ and the United Kingdom ${ }^{17}$ that could be relevant for the Canadian context. We compared the questionnaires selected and then adapted them through 2 processes. First, to achieve context relevance, we identified domains of interest related to the Canadian clinical and cultural context in consultation with a Canadian multidisciplinary team (physicians, ethicists, a jurist, a psychologist and a sociologist). Second, to achieve conceptual clarity, we adapted questions for distinguishing observable medical end-of-life practices with different legal status according to a descriptive classification developed in a concurrent research study. ${ }^{23}$
After comparing the selected questionnaires, ${ }^{11,15,17}$ we decided to document not only the last medical practice performed by physicians before a patient's death but also all other medical practices and the underlying decision-making processes. Our aim was to obtain a more thorough overview of patients' trajectories of care and to better assess practices in line with Canadian legislative frameworks and professional recommendations (e.g., respect of patient's consent). ${ }^{24} \mathrm{We}$ also modified and developed new questions addressing not only medical practices that could hasten a patient's death but also those intended to prolong life, with or without patient consent. The latter are not well documented in Canada, although they may be challenged in court when physicians' opinion conflicts with preferences expressed by patients and their relatives. ${ }^{25}$ Furthermore, although the evidence on double effect (using drugs for symptom management that hastens death) is questioned, ${ }^{26}$ the use of opioids or sedatives at the end of life may extend life expectancy according to some authors. ${ }^{27,28}$ Finally, an important element in determining the legal status of medical practices in Canada is the physician's underlying intention. Results from previous studies suggest that this notion may sometimes be difficult to measure and interpret. ${ }^{29,30}$ A scoping review showed that physicians' intention is not always related to the proportionality of drugs used to relieve suffering or to end a patient's life. ${ }^{23}$ As this discrepancy could lead to misclassification (overestimation or underestimation) of some medical practices, we modified the questionnaire using a descriptive classification scheme developed in a concurrent study ${ }^{23}$ to include questions on both physicians' intention and the adjustment of drugs according to pain and symptom control.

\section{Questionnaire validation}

Physicians were invited to validate the modified questionnaire using the Three-Step Test-Interview. ${ }^{31}$ Initially they were referred by members of the multidisciplinary committee, followed by recruitment by means of the snowball sampling strategy until saturation, when no new information was obtained. To be included in the study, physicians had to be from medical specialties associated with a higher probability of being involved with dying patients (e.g., critical care, emergency medicine, general practice, geriatrics, nephrology, pediatrics, palliative medicine, psychiatry), be from different Canadian regions and be able to understand English.

The participants were instructed to think aloud while they were navigating the instrument and attempting to answer, with follow-up probing by the interviewer to identify problems related to the understanding, wording and order of questions as well as the range of possible answers. We also used debriefing to elicit participants' general experiences and opinions about the questionnaire. Because the questionnaire aimed to document medical practices based on the latest death that the physician had personally attended within the previous 12 months (including potentially illegal acts under legislation at the time of the study), participants were instructed to use a self-chosen fictional case.

The questionnaire tested was in English. It was translated into French by a professional translator and then translated 
back into English by another professional translator blind to the original questionnaire. Bilingual research team members compared the final and original English-language versions to check the validity of the translation. Minor modifications were made to ensure equivalence between the French- and English-language versions. The final questionnaire contained 45 questions in a booklet style (Appendix 1, available at www. cmajopen.ca/content/4/2/E222/suppl/DC1).

\section{Phase 2: pilot study}

\section{Sampling strategy}

Two sampling methods have been used in previous studies of medical end-of-life practices: death certificate sampling ${ }^{4-12,15}$ and registry sampling based on medical specialties. ${ }^{14,16-19}$ Given the fragmented nature of the compilation and management of death certificates in Canada (by each province and territory) and consequent complex and lengthy access procedure, death certificate sampling was deemed unrealistic for a pan-Canadian study. Therefore, clinical experts from our multidisciplinary team classified a comprehensive list of 37 groups of Canadian medical specialties into 3 groups based on the probability of being involved in end-oflife decision-making: high $(n=11)$, low $(n=13)$ or nil $(n=13)$. We drew a stratified sample of 300 Canadian physicians in active practice from Scott's Canadian Medical Directory Online ${ }^{32}$ retired physicians and those in training were excluded. We considered 3 factors in determining sample size: the fact that not all physicians may have treated or attended a patient who had died in the previous 12 months; the low and declining response rate of the National Physician Survey; ${ }^{21}$ and the fact that some questions (e.g., intentional use of lethal drugs) were highly sensitive, and responses could have legal implications for participating physicians. As recommended by Viechtbauer and colleagues, ${ }^{33}$ we then oversampled to obtain at least 59 completed questionnaires, which would allow us to identify unforeseen problems. Physicians belonging to either the high- or low-probability group were included in the sample and were further stratified into 5 practice regions: Atlantic Canada, British Columbia, the Northwest region (prairie provinces and the 3 territories), Ontario and Quebec.

\section{Questionnaire administration}

In previous studies, information was gathered through mailed questionnaire ${ }^{4-12,14-19}$ or Web questionnaire or both. ${ }^{15} \mathrm{We}$ tested participants' preferences by giving them the choice between modes of completion. Initial contact was made by mail in January 2015, in the participants' language of preference as indicated in the medical directory. We compared the participation rate, completion time and answer patterns between the 2 modes of completion.

We used several strategies to maximize the response rate while also considering the sensitive nature of the subject. In accordance with the modified tailored design method, ${ }^{34}$ we used a 5-contact procedure: prenotice letter, introduction letter with consent form and questionnaire, thank you card, reminder letter with consent form and replacement questionnaire, and last reminder letter. We sent the documents at weekly intervals, and stamped return envelopes accompanied questionnaires. To ensure anonymity, the paper questionnaire, envelopes and online survey link did not include any identification marks that could provide information about respondents. This measure required that reminders be sent to all participants since it was impossible to identify nonrespondents. Only limited sociodemographic information was requested, and some characteristics (medical specialty and region of practice) were combined to avoid indirect identification by coupling answers.

Ethics approval was obtained from the Research Ethics Board of the University of Ottawa.

\section{Statistical analysis}

To verify feasibility-related objectives, we used frequency distributions for participation and completion rates, and characterized completion time using means and SDs. To assess representativeness, we compared study participants with the overall sample using $\chi^{2}$ tests because the anonymity provided to participants made it impossible to identify who had and had not responded. We analyzed the data using SPSS, version 20.

\section{Results}

\section{Phase 1}

\section{Questionnaire validation}

Of the 49 physicians invited to the cognitive interview, $20 \mathrm{did}$ not respond, 9 refused to participate, 1 did not show up, and 5 were on a waiting list owing to scheduling conflicts when saturation was reached. The 14 participants were from 5 provinces (British Columbia, Manitoba, Nova Scotia, Ontario and Quebec). Telephone interviews were conducted over 3 rounds in French or English between April and October 2014. The average interview length was 30 minutes.

\section{Understandability of questions}

Based on feedback from the 14 physicians, we reformulated questions to enhance clarity and added multiple answers or nonapplicable choices when appropriate. Most of the questions were not originally applicable in the case of the death of a child and were modified accordingly. Several participants remarked on the relevance of eliciting information about medical treatments or decisions that could prolong life as well as hasten death, as our questionnaire did. Participants clearly understood changes made to the original questionnaires, including questions on underlying intention and the proportionality of drugs used for pain and symptom management. Box 1 gives a summary of the most important changes made to the questionnaire.

\section{Phase 2}

Between January and April 2015, 13 envelopes (4.3\%) were returned to sender, 1 physician asked to no longer be contacted after the prenotice mailing, 5 physicians said they did 


\section{Box 1: Most important changes to the questionnaire}

\section{Terminology and conceptual changes}

1) Questions related to intention

- removed the qualifying adjectives "partly" and "explicit"

- changed the formulation "hasten the end of the patient's life" to "influence the timing of death"

- added a new question on the proportionality of drugs (to combine the intention and the means used)

2) Question related to the expressed desire of the patient: 2 options: delay the occurrence of death in addition to advance the occurrence of death

\section{Structural changes}

1) Documentation of the underlying decision-making process for each medical act (not only the last one performed)

2) Medical act of sedation was integrated in the section with other medical acts (rather than in a question at the end of the questionnaire)

3) Separate documentation of withholding and withdrawing treatment(s)

\section{Additions}

1) As in the French questionnaire, ${ }^{15}$ we measured the medical acts regarding the continuation of life-sustaining treatment(s)

2) Separate section to measure the use of drugs other than opioids and sedatives

3) Question to identify patients of Aboriginal descent

4) Question regarding challenges during the process of end-oflife care related to cultural differences, language barrier, different religious beliefs or conflict between family members

not feel concerned by the subject, and 1 physician answered that he did not take part in any kind of survey (Figure 1). The valid initial sample thus consisted of 280 physicians. Of the 87 respondents, 11 declined to participate in the survey (Figure $1)$. Therefore, the response rate was $27.1 \%(n=76)$, with most respondents (64 [84\%]) completing the questionnaire by mail. Almost a third (19 [31\%]) of those who completed the paper questionnaire said they would not have answered if the survey had been available only online. Figure 2 shows the patterns of response (including those who declined to participate) over the data collection period.

\section{Response patterns}

Of the 12 participants who responded via the Web, 2 did not complete the survey (completion rate $83 \%$ ); the 10 others answered all the questions. None of the respondents who answered the paper questionnaire returned an incomplete questionnaire. Few problems of completion were found. Unanswered questions were rare, ranging from 1 to 3 occurrences per question, according to the following patterns: screening questions were answered, but subsequent documentation was missing or partly missing; or screening questions were unanswered, but subsequent documentation was provided. Sensitive questions did not have more missing data than other questions. All potentially incriminating questions were answered. For example, of the 31 participants who reported administering opioids in the last 24 hours of life, 7 $(23 \%)$ indicated that "opioids were used above what was needed for pain and symptom control." Three of the 7 thought that the decision to use opioids had hastened the person's death, and 1 indicated that the intention was to influence the timing of death. For some questions (e.g., cause of death or who administrated opioids), participants provided multiple answers when only 1 was expected, and, in fewer cases, participants provided answers other than those suggested on the questionnaire.

\section{Comparability of participants to overall sampling frame}

No statistically significant difference was found between the 76 participants and the overall sample $(n=300)$ in sex $\left(\chi^{2}=\right.$ $0.09, p=0.77)$, age $\left(\chi^{2}=4.51, p=0.34\right)$, language $\left(\chi^{2}=0.913\right.$, $p=0.34)$, medical specialty $\left(\chi^{2}=2.43, p=0.12\right)$ or region of practice $\left(\chi^{2}=4.06, p=0.41\right)$ (Table 1$)$. Although the difference was not statistically significant, family physicians tended to be less likely than specialists to respond. Physicians younger than 35 years of age seemed most likely to respond and to complete the questionnaire on the $\mathrm{Web}\left(\chi^{2}=\right.$ $5.12, p<0.05)$, and francophones and those practising in Quebec seemed more likely to respond than anglophones and physicians from other regions.

\section{Questionnaire completion time}

The mean completion time was 17 minutes for those who had been the attending physician in the case of a death in the previous 12 months and 4 minutes for those who had not. There was no difference in completion time between the paper and online questionnaires $(t=0.2,65$ degrees of freedom, $p=0.85$ ).

\section{Interpretation}

Using existing questionnaires from previous studies on medical end-of-life practices, ${ }^{11,15,17}$ we were able to modify questions to improve relevance and clarity in a Canadian context. Despite the low response rate, we found that physicians were as likely to respond to sensitive questions as to other questions, and we did not detect any differences in sociodemographic variables between the participants and the overall sample.

Although the difference was not statistically significant, family physicians tended to be less likely than specialists to participate in the survey. Based on observations from the cognitive interviews, this trend may have been due to differences in Canadian medical specialty designation (i.e., professional classification) and in how physicians identify themselves (e.g., palliative care physicians and gerontologists were classified as family physicians in professional directories but identified themselves as specialists). Potential problems linked to these discrepancies partly result from the anonymous nature of our research procedure. As such, the results of any future large study will have to be interpreted with caution. The finding that those younger than 35 years of age seemed most likely to respond and to complete the questionnaire on the Web justifies the use of the 2 modes of administration despite the fact that most of the respondents preferred the paper questionnaire. Finally, the finding that francophones and those practising in Quebec seemed more likely to respond may have been 


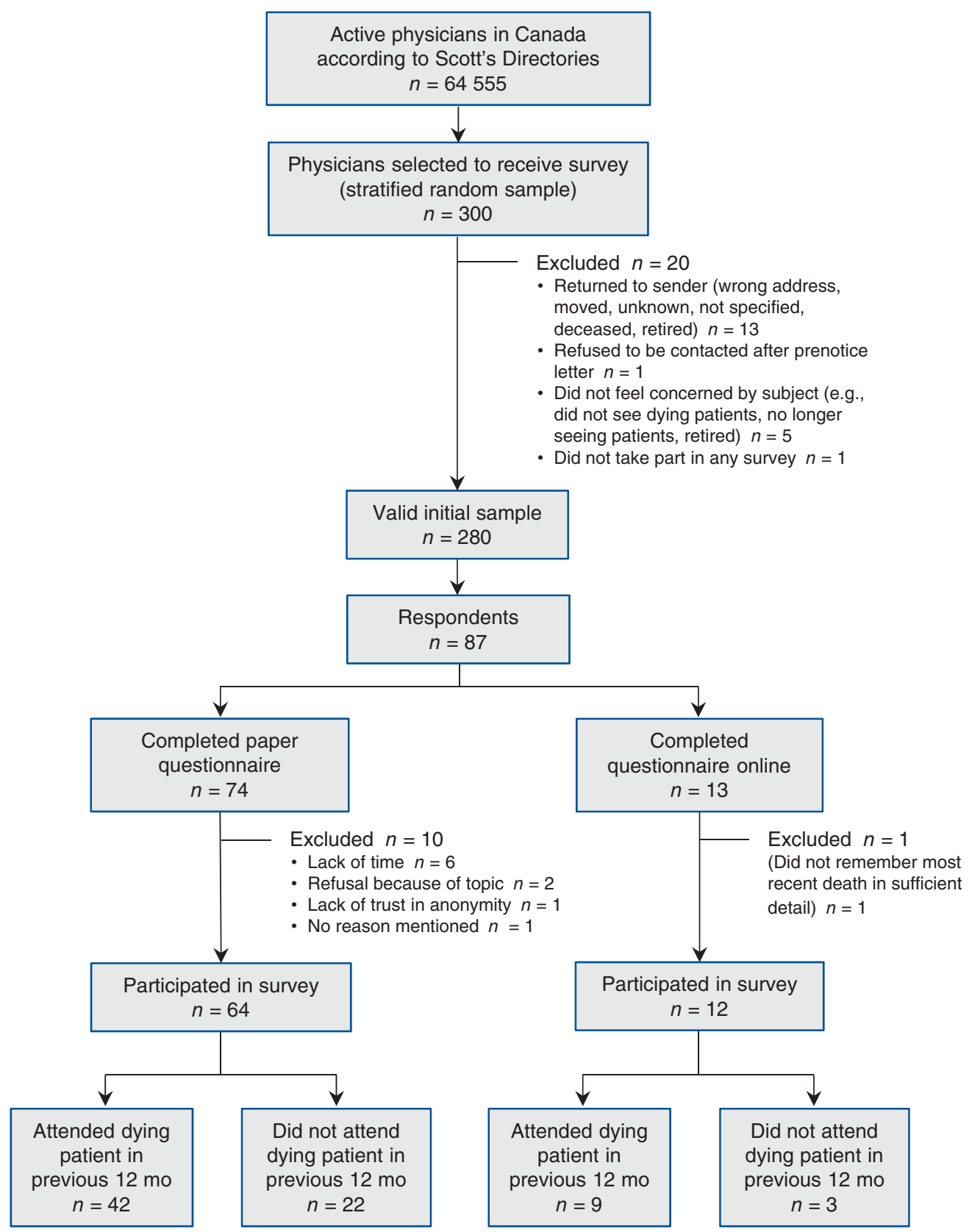

Figure 1: Flow diagram of the selection of study participants.

due to the fact that most French-speaking Canadians live in Quebec, where physicians may be more sensitized to the subject of physician-assisted death owing to long-standing debates around end-of-life care and recent legislation change (e.g., An Act Respecting End-of-life Care ${ }^{1}$ in June 2014).

As shown by the cognitive interviews, physicians clearly understood modifications made to the original questionnaires, including questions on life-sustaining treatment, underlying intention and the proportionality of drugs used for pain and symptom management. Although these changes decreased possible comparability with previous studies, ${ }^{4-12,14-19}$ they increased the validity and relevance of our findings for the Canadian context, allowed a more thorough appreciation of end-of-life care trajectories and reduced risks of misclassification. ${ }^{23}$ The fact that respondents provided answers consistently throughout the questionnaire, even for 


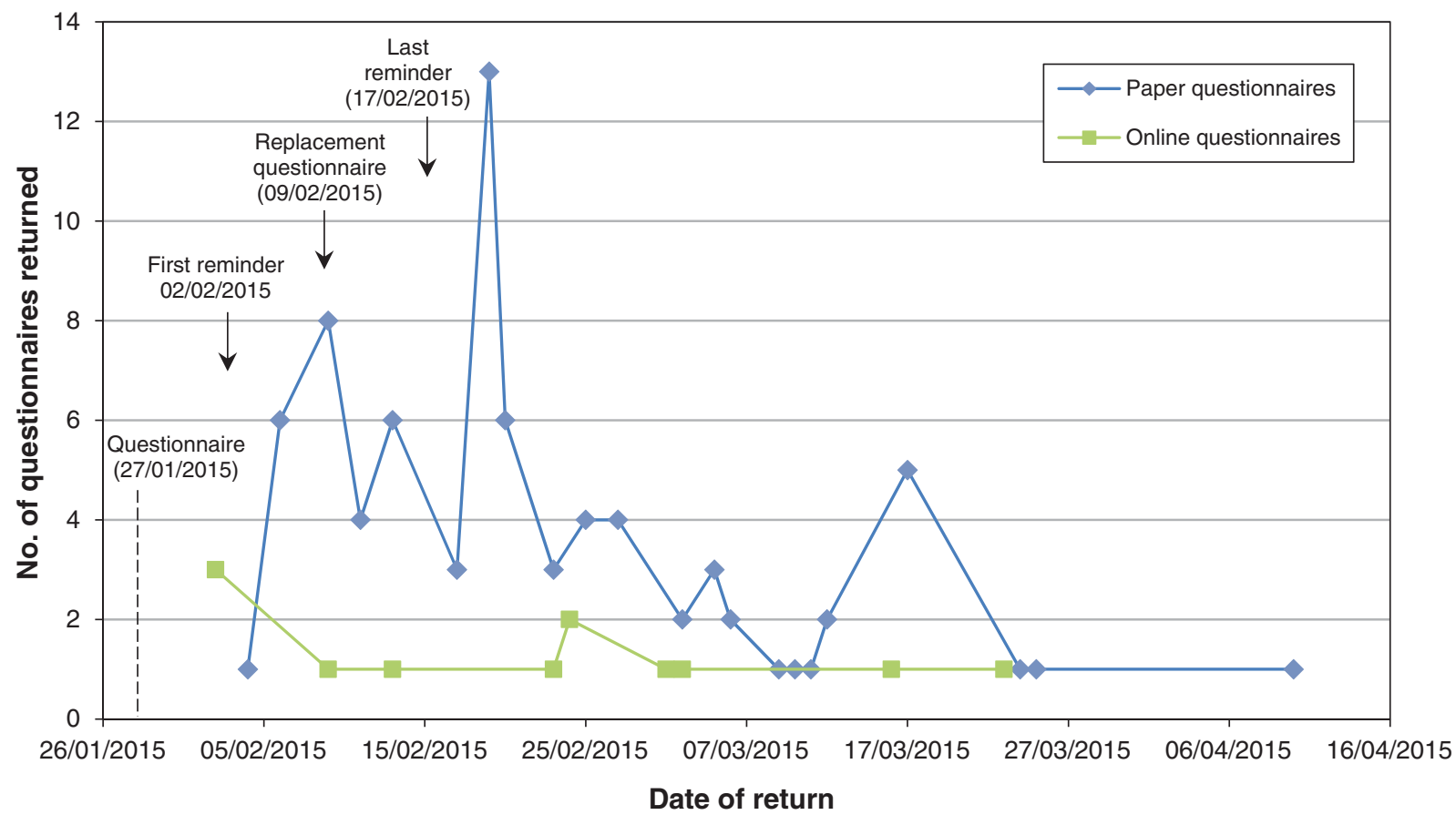

Figure 2: Number of questionnaires returned during the data collection period, including refusals to participate.

the most sensitive and legally controversial questions, is another strong indication of the feasibility of conducting a larger study in Canada.

Although we devoted considerable attention to attempting to maximize the participation rate using the modified tailored design method, ${ }^{34}$ certain modifications (e.g., no first-class mail, no personalized letter) were necessary to ensure anonymity. Based on a systematic review of methods that increase rates of response to postal questionnaires, ${ }^{35}$ we followed recommendations such as choosing an interesting questionnaire topic, sending a prenotice letter, making follow-up contact and providing a stamped return envelope with a second copy of the questionnaire. However, we did not follow all the prescribed recommendations; ${ }^{35}$ for instance, we did not use incentives owing to limited resources. Nevertheless, the link between these recommendations and higher response rates remains to be further elucidated, as several studies conducted with physicians have given inconsistent findings. Some have shown that questionnaire length ${ }^{36}$ and the use of incentives ${ }^{37,38}$ have a threshold effect on response rate, but others have suggested that reducing questionnaire length ${ }^{39-41}$ and using incentives $^{40,41}$ does not make a significant difference. Moreover, a randomized trial conducted with questionnaires on a topic similar to ours, in a comparable population, showed no significant difference in response rate between a longer questionnaire (54 questions) and a shorter questionnaire (27 questions). ${ }^{39}$ It is thus unlikely that the slightly greater length of our questionnaire (45 questions) compared with the 3 questionnaires ${ }^{11,15,17}$ on which we based ours ( 2 of which contained
34 questions and 1 of which contained 40) had a significant impact on our response rate.

In comparison with similar studies conducted in other countries, ${ }^{4-12,14-19}$ our response rate $(27 \%)$ is low. However, it is comparable to and even higher than rates obtained in other national studies conducted among Canadian physicians. ${ }^{21,40}$ Knowing the response rate is also helpful to determine the adequate sample size for a large national study.

\section{Limitations}

There are a number of study limitations. A first barrier stems from the sensitive nature of the topic. In ensuring anonymity (e.g., by combining answer categories for regions and specialties with fewer physicians) for maximal survey participation, we decreased our ability to verify representativeness and generalize our findings. Also, we cannot rule out the possibility of social desirability bias, owing to fear of prosecution. However, we hypothesize that interest in participating may have been strong because the study was conducted during debates on medical end-of-life practices in Canada. Third, an important limitation of having a low response rate is that it increases the risk of nonresponse bias. However, previous studies have shown that physician surveys are more robust to nonresponse bias than surveys conducted in the general population. ${ }^{42-47}$ In addition, the sociodemographic characteristics of our participants were comparable to those of the sampling frame. Consequently, we do not expect our low response rate to have translated into higher nonresponse bias. Other study limitations relate to survey design methods and to time and financial 


\begin{tabular}{|c|c|c|c|}
\hline \multirow[b]{2}{*}{ Characteristic } & \multicolumn{2}{|c|}{ No. (\%) of physicians } & \multirow[b]{2}{*}{$p$ value } \\
\hline & $\begin{array}{l}\text { Overall sample } \\
\qquad(n=300)\end{array}$ & $\begin{array}{l}\text { Participants } \\
\quad(n=76)\end{array}$ & \\
\hline \multicolumn{4}{|l|}{ Sex } \\
\hline Male & $186(62.0)$ & $48(63.2)$ & \multirow[t]{2}{*}{0.77} \\
\hline Female & $114(38.0)$ & 27 (35.5) & \\
\hline Unknown & 0 & $1(1.3)$ & \\
\hline \multicolumn{4}{|l|}{ Age, yr } \\
\hline$<35$ & $23(7.7)$ & $14(18.4)$ & \multirow[t]{5}{*}{0.34} \\
\hline $36-45$ & $71(23.7)$ & $18(23.7)$ & \\
\hline $46-55$ & $76(25.3)$ & $17(22.4)$ & \\
\hline $56-65$ & $72(24.0)$ & $15(19.7)$ & \\
\hline$>65$ & $55(18.3)$ & $12(15.8)$ & \\
\hline Unknown & $3(1.0)$ & 0 & \\
\hline \multicolumn{4}{|l|}{ Language } \\
\hline English & $229(76.3)$ & $53(69.7)$ & \multirow[t]{2}{*}{0.34} \\
\hline French & $71(23.7)$ & $23(30.3)$ & \\
\hline \multicolumn{4}{|l|}{ Medical specialty } \\
\hline Family medicine/general practice & $175(58.3)$ & $35(46.0)$ & \multirow[t]{2}{*}{0.12} \\
\hline Other & $125(41.7)$ & $40(52.6)$ & \\
\hline Unknown & 0 & $1(1.3)$ & \\
\hline \multicolumn{4}{|l|}{ Region } \\
\hline $\begin{array}{l}\text { Atlantic Canada (New Brunswick, } \\
\text { Nova Scotia, Prince Edward } \\
\text { Island, Newfoundland and } \\
\text { Labrador) }\end{array}$ & $21(7.0)$ & $5(6.6)$ & \multirow[t]{5}{*}{0.41} \\
\hline British Columbia & $39(13.0)$ & $4(5.3)$ & \\
\hline $\begin{array}{l}\text { Northwest region (Alberta, } \\
\text { Saskatchewan, Manitoba, Yukon } \\
\text { Territory, Northwest Territories, } \\
\text { Nunavut) }\end{array}$ & $54(18.0)$ & $14(18.4)$ & \\
\hline Ontario & $110(36.7)$ & $31(40.8)$ & \\
\hline Quebec & $76(25.3)$ & $22(28.9)$ & \\
\hline
\end{tabular}

considerations. To maximize study participation for a future large national study, we recommend having a longer interval (2-4 weeks) between the last 2 contacts (replacement questionnaire and last reminder), as suggested by Dillman and colleagues. ${ }^{34}$ Finally, although there is disagreement in the literature on the cost-effectiveness of various types of incentives with physicians, monetary incentives should be attempted. ${ }^{40,41,48}$

\section{Conclusion}

In this pilot study we were able to successfully modify existing questionnaires designed to measure the prevalence of medical end-of-life practices and the underlying decision-making pro- cesses, and to successfully administer them. Consequently, we were able to determine that it is indeed feasible to study these practices in Canada, even those that are currently illegal. Identification of the response rate will be useful for sample size calculations for larger studies. Additional strategies such as longer intervals between contacts and the use of incentives will be required to enhance the participation rate. Such studies are needed to further our understanding of how decisions are made before death, to identify potential areas of improvement and training needs, to study the effect of policy changes on medical end-of-life practices and to monitor their developments over time. 


\section{References}

1. Bill $n^{\circ}$ 52: An Act respecting end-of-life care. Québec: National Assembly of Quebec; 2014. Available: www.assnat.qc.ca/en/travaux-parlementaires/projets-loi/ projet-loi-52-41-1.html (accessed 2015 Aug. 5).

2. Carter v. Canada (Attorney General) 2013 BCCA 435. Available: https://scc-csc. lexum.com/scc-csc/scc-csc/en/item/14637/index.do (accessed 2015 Aug. 5).

3. Bill C-14. An Act to amend the Criminal Code and to make related amendments to other Acts (medical assistance in dying). Ottawa: Ministry of Justice; 2016. Available: www.parl.gc.ca/HousePublications/Publication.aspx?Language=E\&Mode =1\&DocId=8183660 (accessed 2016 Apr. 25).

4. van der Maas PJ, van Delden JJ, Pijnenborg L. Euthanasia and other medical decisions concerning the end of life. An investigation performed upon request of the Commission of Inquiry into the Medical Practice concerning Euthanasia. Health Policy 1992;21:vi-x, 1-262.

5. van der Maas PJ, van der Wal G, Haverkate I, et al. Euthanasia, physicianassisted suicide, and other medical practices involving the end of life in the Netherlands, 1990-1995. N Engl F Med 1996;335:1699-705.

6. Onwuteaka-Philipsen BD, van der Heide A, Koper D, et al. Euthanasia and other end-of-life decisions in the Netherlands in 1990, 1995, and 2001. Lancet 2003;362:395-9.

7. van der Heide A, Onwuteaka-Philipsen BD, Rurup ML, et al. End-of-life practices in the Netherlands under the Euthanasia Act. N Engl 7 Med 2007; 356:1957-65

8. Onwuteaka-Philipsen BD, Brinkman-Stoppelenburg A, Penning C, et al. Trends in end-of-life practices before and after the enactment of the euthanasia law in the Netherlands from 1990 to 2010: a repeated cross-sectional survey. Lancet 2012;380:908-15

9. Deliens L, Mortier F, Bilsen J, et al. End-of-life decisions in medical practice in Flanders, Belgium: a nationwide survey. Lancet 2000;356:1806-11.

10. van der Heide A, Deliens L, Faisst K, et al.; EURELD consortium. End-oflife decision-making in six European countries: descriptive study. Lancet 2003;362:345-50.

11. Bilsen J, Cohen J, Chambaere K, et al. Medical end-of-life practices under the euthanasia law in Belgium. NEngl 7 Med 2009;361:1119-21.

12. Chambaere K, Vander Stichele R, Mortier F, et al. Recent trends in euthanasia and other end-of-life practices in Belgium. N Engl 7 Med 2015;372:1179-81.

13. Ministère de la Justice belge. Loi relative à l'euthanasie du 28 mai 2002. Available: www.health.belgium.be/internet2Prd/groups/public/@public/@dg1/@acutecare/ documents/ie2law/14888537.pdf (accessed 2015 Aug. 5).

14. Kuhse H, Singer P, Baume P, et al. End-of-life decisions in Australian medical practice. Med F Aust 1997;166:191-6.

15. Pennec S, Monnier A, Pontone S, et al. End-of-life medical decisions in France: a death certificate follow-up survey 5 years after the 2005 act of parliament on patients' rights and end of life. BMC Palliat Care 2012;11:25.

16. Seale C. National survey of end-of-life decisions made by UK medical practitioners. Palliat Med 2006;20:3-10.

17. Seale C. End-of-life decisions in the UK involving medical practitioners. Palliat Med 2009;23:198-204.

18. Meier DE, Emmons CA, Wallenstein S, et al. A national survey of physicianassisted suicide and euthanasia in the United States. N Engl 7 Med 1998;338: 1193-201.

19. Mitchell K, Owens RG. National survey of medical decisions at end of life made by New Zealand general practitioners. BM7 2003;327:202-3.

20. Schoen C, Osborn R, Doty MM, et al. A survey of primary care physicians in eleven countries, 2009: perspectives on care, costs, and experiences. Health Aff (Millwood) 2009;28:w1171-83

21. National Physician Survey, 2004-2014. Ottawa: Canadian Medical Association; 2010. Available: http://nationalphysiciansurvey.ca/surveys/ (accessed 2015 Aug. 5).

22. Thabane L, Ma J, Chu R, et al. A tutorial on pilot studies: the what, why and how. BMC Med Res Methodol 2010;10:1

23. Boivin A, Marcoux I, Garnon G, et al. Comparing end-of-life practices in different policy contexts: a scoping review. 7 Health Serv Res Policy 2015;20:115-23.

24. CMA code of ethics. Ottawa: Canadian Medical Association; 2004. Available: http:// policybase.cma.ca/dbtw-wpd/PolicyPDF/PD04-06.pdf (accessed 2015 Aug. 5).

25. Cuthbertson v. Rasouli, 2013 SCC 53 1; 2013. Available: http://scc-csc.lexum.com/ decisia-scc-csc/scc-csc/scc-csc/en/item/13290/index.do (accessed 2015 Aug. 5).

26. López-Saca JM, Guzmán JL, Centeno C. A systematic review of the influence of opioids on advanced cancer patient survival. Curr Opin Support Palliat Care 2013;7:424-30.

27. Bakker J, Jansen TC, Lima A, et al. Why opioids and sedatives may prolong life rather than hasten death after ventilator withdrawal in critically ill patients. Am 7 Hosp Palliat Care 2008;25:152-4.

28. Sykes N, Thorns A. Sedative use in the last week of life and the implications for end-of-life decision making. Arch Intern Med 2003;163:341-4.

29. Smets T, Cohen J, Bilsen J, et al. The labelling and reporting of euthanasia by Belgian physicians: a study of hypothetical cases. Eur 7 Public Health 2012; 22:19-26.

30. Chambaere K, Bilsen J, Cohen J, et al. Physician-assisted deaths under the euthanasia law in Belgium: a population-based survey. CMA7 2010;182:895-901.

31. Hak T, van der Veer K, Jansen H. The Three-Step Test-Interview (TSTI): an observation-based method for pretesting self-completion questionnaires. Surv Res Methods 2008;2:143-50.

32. Scott's Canadian medical directory. Available: https://secure.scottsdirectories.com/ Search/SearchDetail/1295 (accessed 2016 Apr. 25).

33. Viechtbauer W, Smits L, Kotz D, et al. A simple formula for the calculation of sample size in pilot studies. 7 Clin Epidemiol 2015;68:1375-9.

34. Dillman DA, Smith JD, Christian LM. Internet and mail surveys: the tailored design method. New York: John Wiley; 2007. p. 149-93.

35. Edwards PJ, Roberts I, Clarke M, et al. Methods to increase response rates to postal questionnaires. Cochrane Database Syst Rev 2009;(3):MR000008.

36. Jepson C, Asch DA, Hershey JC, et al. In a mailed physician survey, questionnaire length had a threshold effect on response rate. 7 Clin Epidemiol 2005;58:103-5.

37. Baron G, De Wals P, Milord F. Cost-effectiveness of a lottery for increasing physicians' responses to a mail survey. Eval Health Prof 2001;24:47-52.

38. Abdulaziz K, Brehaut J, Taljaard M, et al. National survey of physicians to determine the effect of unconditional incentives on response rates of physician postal surveys. BM7 Open 2015;5:e07166

39. Bolt EE, van der Heide A, Onwuteaka-Philipsen BD. Reducing questionnaire length did not improve physician response rate: a randomized trial. 7 Clin Epidemiol 2014;67:477-81.

40. Grava-Gubins I, Scott S. Effects of various methodologic strategies: survey response rates among Canadian physicians and physicians-in-training. Can Fam Physician 2008;54:1424-30.

41. Cottrell E, Roddy E, Rathod T, et al. Maximising response from GPs to questionnaire surveys: Do length or incentives make a difference? $B M C \mathrm{Med}$ Res Methodol 2015;15:3.

42. Kellerman SE, Herold J. Physician response to surveys. A review of the literature. Am F Prev Med 2001;20:61-7.

43. Barclay S, Todd C, Finlay I, et al. Not another questionnaire! Maximizing the response rate, predicting non-response and assessing non-response bias in postal questionnaire studies of GPs. Fam Pract 2002;19:105-11.

44. Cull WL, O'Connor KG, Sharp S, et al. Response rates and response bias for 50 surveys of pediatricians. Health Serv Res 2005;40:213-26.

45. Menachemi N, Hikmet N, Stutzman M, et al. Investigating response bias in an information technology survey of physicians. 7 Med Syst 2006;30:277-82.

46. McFarlane E, Olmsted MG, Murphy J, et al. Nonresponse bias in a mail survey of physicians. Eval Health Prof 2007;30:170-85

47. Bjertnaes OA, Garratt A, Botten G. Nonresponse bias and cost-effectivenes in a Norwegian survey of family physicians. Eval Health Prof 2008;31:65-80.

48. VanGeest JB, Johnson TP, Welch VL. Methodologies for improving response rates in surveys of physicians: a systematic review. Eval Health Prof 2007;30:303-21.

Affiliations: Interdisciplinary School of Health Sciences, Faculty of Health Sciences (Marcoux, Mesana) and School of Epidemiology, Public Health \& Preventive Medicine, Faculty of Medicine (Graham), University of Ottawa, Ottawa, Ont.; Department of Family Medicine, Faculty of Medicine (Boivin), University of Montreal Hospital Research Centre, Montréal, Que.; Centre de recherche du centre hospitalier de l'Université de Montréal (Hébert), Montréal, Que.

Contributors: Isabelle Marcoux conceived the study, supervised data collection, performed the statistical analysis, interpreted the results, wrote the first draft and revised the manuscript. Laura Mesana participated in data collection and interpretation, statistical analysis and manuscript revision. Antoine Boivin, Ian Graham and Paul Hébert participated in study conception, data interpretation and manuscript revision. All of the authors approved the final version submitted for publication and agreed to act as guarantors of the work.

Funding: This research project was supported by the Canadian Institutes of Health Research (grant no. FRN: 129929).

Acknowledgments: We thank Julie K. Campbell and Mirhad Lončar for their help with study design, recruitment and data collection. Members of the advisory committee included Jeff Blackmer (Canadian Medical Association), Marie-Eve Bouthiller and Delphine Roigt (Association québécoise en éthique clinique) and Pierre Deschamps. Some members of the advisory committee requested that their contribution remain anonymous. We also thank Clive Seale for sharing his experience and documentation regarding studies on medical end-of-life practices using registry sampling based on medical specialties. We are grateful to the experts who helped with questionnaire development, the physicians who participated in the cognitive interviews and the physicians who completed the questionnaire.

Supplemental information: For reviewer comments and the original submission of this manuscript, please see www.cmajopen.ca/content/4/2/ E222/suppl/DC1 